From the Department of Child Health, Medical School University of Gadjah Mada and BP4, Yogyakarta.

\title{
Positive Tuberculin and Primary Tuberculosis. Frequency among Non-BCG Children of $0-4$ years (Preliminary Report)
}

\author{
by \\ JATI SOENARTO, ACHMAD SURJONO, DJAUHAR ISMAIL, \\ SUNARTINI and SOEKARDI DIRDJOHUSODO.
}

\begin{abstract}
\end{abstract}
The tuberculin test, röntgen photos, and nutritional condition of babies and pre-school children admitted to the Department of Child Health, University of Gadjah Mada Hospital, revealed:

- A very high tuberculin index among the children examined, especially those under one year of age, much higher than the figures ever to be reported in Indonesia.

- A direct correlation between the size of induration and the likelihood of finding pulmonary abnormalities.

- A close relationship between deficient nutritional status and röntgenologic abnormalities of the lungs.

We think that deficient nutritional status develops due to the presence of tuberculosis infection. Based on the factors mentioned above, in the national campaign against tuberculosis the following should be considered:

- BCG at the earliest possible moment (neonatal period/life).

- INH chemoprophylactic to all positive contact children will effectively prevent clinical manifestation as well as improve nutritional status. 


\section{Introduction}

In Indonesia tuberculosis still constitutes one of the most serious problems in public health. It will no longer be a problem when the tuberculin index among children under 14 years of age is less than $1 \%$ (WHO Expert Committee on Tuberculosis, 1959 - cited by Shenan, 1968). Unfortunately, this tuberculin index in Indonesia among children is still far above this level. The result of tuberculin testing during 10 years performed among more than 10 million people throughout the Indonesian archipelago (1952 - 1962) showed a tuberculin index of $22.3 \%$ in the 1 6 years age group and $42.7 \%$ in the $7-14$ years age group (Samallo, 1958).

This preliminary report presents : results of tuberculin test, röntgenographic examinations of the lungs, and nutritional condition of children aged $0-4$ years who have not yet received BCG. Our attention is focused on infants under the age of one year. The aims of the investigation are:

- To study the frequency of tuberculin positivity in infants and preschool cliildren who have not received BCG

- To compare the relationship between the induration index and röntgenographic abnormality in the infant group

- To investigate the assumption that a close relationship exists between mal. nutrition and the possibility of suffering from tuberculosis.

\section{Material and methods}

Mantoux tuberculin test was appli to 245 children aged $0-4$ years visite to the well Baby Clinic, Department Child Health, University of Gadjal Mada Hospital. Of these children, 18; were under one year of age. Absena of BCG vaccination was confirmed b history and absence of any scar. Tube: culin test was done by intradermal injec tion (Mantoux) using Old Tuberculin $0.1 \mathrm{ml} ., 10$ T.U. (solution 1/1,000), product of PN Biofarma Bandung. special syringe was used for tuberculi test with no. 26 needle (the injectio was done by a nurse). Volar surface injection was given about the middle of the left forearm. Induration was mea. sured on the 3rd day with a transparent ruler using visual and palpation verifi. cation of transverse dimension.

Children with tuberculin reaction $(\geqslant$ $10 \mathrm{~mm}$.) were regarded as positive, and an antero-posterior thorax photo of them was taken. The photo reading was don by two groups of independent readers Group I was a physician from BP4, whe reas Group II consisted of doctors from the Department of Child Health, Uni versity of Gadjah Mada Hospital. Half of the X-ray photos were sent to $\mathrm{Dr}$ Shirley Roberts, Director of Radiology, Monath University Medical School Prince Henry's Hospital, Melbourne Australia.

Nutritional classification was based on the standard of Gomez et al. (1956) using Indonesian normal weight for age (Dep. Kes., 1971).

\section{Results}

Of the 245 children between $0-4$ years of age, $152(62 \%)$ of them had induration of $\geqslant 10 \mathrm{~mm}$. Of the 245 children, 188 were less than 1 year old, and this number $95(50.6 \%)$ of them were found to have an induration of $\geqslant 10 \mathrm{~mm}$. (Fig. 1).

The results of the röntgen photos are shown on Table 1

- Of 152 children between $0-4$ years of age with positive tuberculin 106 of them were determined by Reader I to have lung changes which were assumed to be a process of tuberculosis. Reader II felt that only 109 of the film were interpretable, $60(55 \%)$ of which were read as tuberculous process. Both groups agreed with the diagnosis of tuberculosis in 49 children (45\%).

- 95 children under one year of age had positive tuberculin tests. Reader

TABLE 1: Percentage of radiographic abnormalities in the lungs

\begin{tabular}{l|c|c}
\hline & $0-4$ years & under 1 year \\
\hline Reader I & $70 \%$ & $67 \%$ \\
Reader II & $55 \%$ & $53 \%$ \\
Both readers & $45 \%$ & $50 \%$ \\
\hline
\end{tabular}

1 found 64 children $(67 \%)$ with abnormalities in the lungs. Reader II found 46 children $(53 \%$ ) (of 83 photos which could be read) with abnormalities in the lungs. Both readers agreed that 41 children $(50 \%)$ showed abnormalities in the lungs.

The interpretation of about two thirds of the cases by Prince Henry's Hospital was similar to that of both readers. A relationship was found between induration and the percentage of röntgeno. logical abnormality. All the children were grouped according to Gomez nutritional classification (Gomez et al., 1956). The results reveals a relationship between malnutrition with positive tuberculin and demonstrable tuberculous lesion in the lung (Fig. 3). Specific treatment was given without any special attention to extra feeding and follow up was done monthly. Twenty-two of 32 cases showed satisfactory increase of body weight during one year of follow up. 


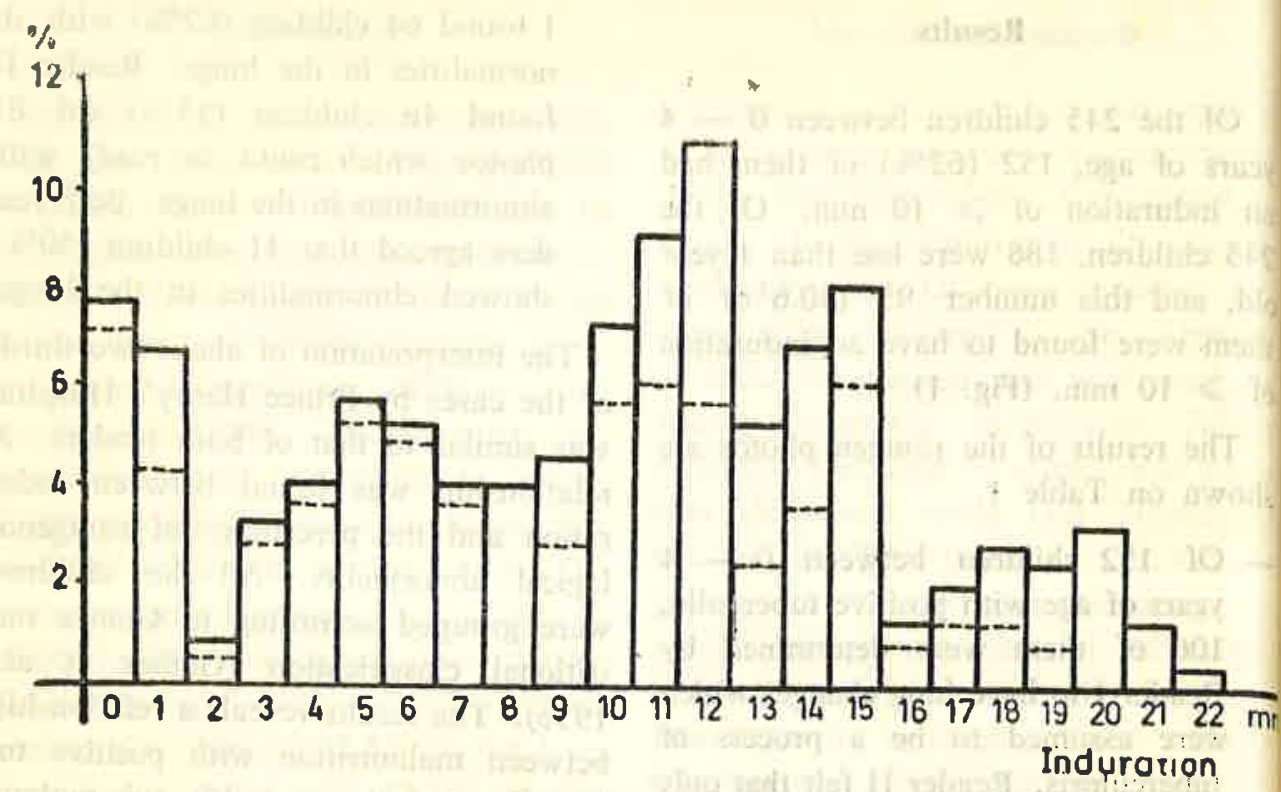

Fig. 2

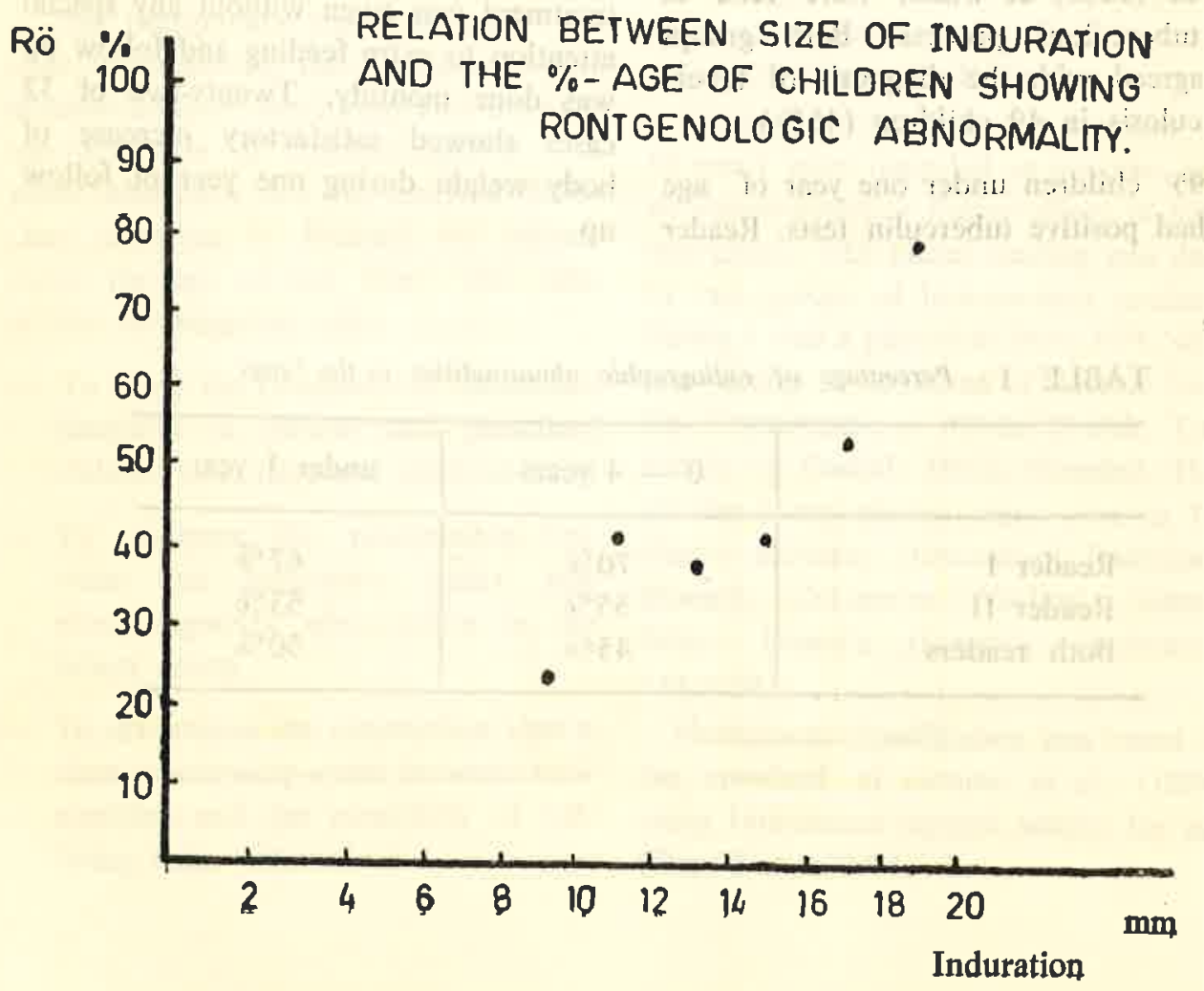

Fig. 3 Relation betweEn tUberCulin ReAction, AND GOMEZ CLASSIFICATION

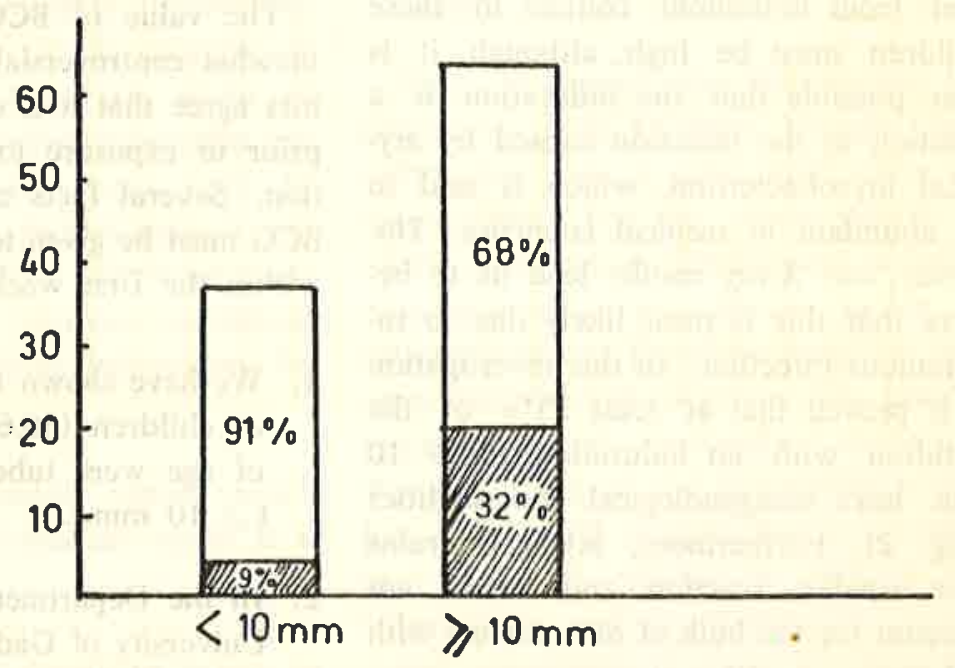

Fig. 4.

RELATION BETWEEN POSITIVE TUBERCULIN ( $\geqslant 10 \mathrm{MM})$ REACTION, GOMEZ CLASSIFICATION AND RONTGENOLOGIC ABNORMALITY

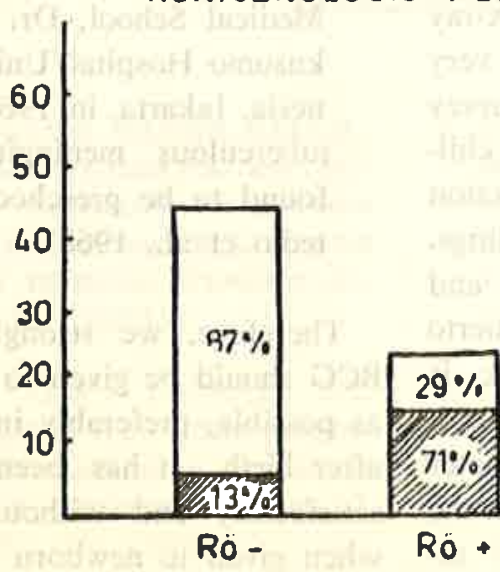




\section{Discussion}

Compared with the figures previously reported in Indonesia, the high frequency of positive tuberculin with Old Tuberculin in babies and preschool-age children proves that tuberculosis infection from household contact in these children must be high, although it is also possible that the induration is a reaction to the infection caused by atypical mycobacterium, which is said to be abundant in tropical countries. However, our X-ray results lead us to believe that this is most likely due to tuberculous infection. In this investigation it is proved that at least $25 \%$ of the children with an induration of $\geqslant 10$ $\mathrm{mm}$. have röntgenological abnormalities (Fig. 2). Furthermore, atypical strains give smaller reaction and would not account for the bulk of our patients with induration $>10 \mathrm{~mm}$.

A previous report from Semarang showed that among children aged $0-2$ years with positive tuberculin reaction, $72 \%$ showed abnormality on X-ray (Liem Tjay Tie, 1955). This is very similar to the results of our survey which revealed that over half the children with positive tuberculin reaction had abnormal röntgenological findings. A 20-year follow up of children and adults with positive tuberculin in Puerto Rico proved that the greatest risk is found among children under 4 years old. It was also proven that the greater the induration, the greater, is the possibility to be infected by the di- sease in later life (Comstock et al, 1974). Thus all the non BCG chil. dren with an induration of $\geqslant 10$ $\mathrm{mm}$. should be given INH chema prophylactic for at least 1 year with proper follow up.

The value of BCG protection is sa mewhat controversial but all investigators agree that it is only useful if given prior to exposure to tuberculous infec. tion. Several facts clearly indicate that BCG must be given to Indonesian babies within the first week of life :

1. We have shown that a great number of children $(50.6 \%)$ under 1 year of age were tuberculin test positive $(\geqslant 10 \mathrm{~mm}$.).

2. In the Department of Child Health University of Gadjah Mada Hospital, during 1972 and $1973,75 \%$ of the tuberculous cases were between the age of $0-4$ years.

3. In the Department of Child Health Medical School, Dr, Cipto Mangunkusumo Hospital/University of Indonesia, Jakarta, in $1968,82.5 \%$ of al tuberculous meningitis cases were found to be preschool children (Sutedjo et al., 1968).

Therefore, we strongly suggest that BCG should be given to babies as early as possible, preferably in the first week after birth. It has been shown to be satisfactory and without complications when given to newborn babies in Indo- nesia (Sutedjo, 1965; Abdul Rifai et al., 1971). Only if the child is protected from birth can the high rate of incidence of tuberculosis in the first year be reduced.

of the 49 children with positive tu. berculin and demonstrable tuberculous lesion, 35 of them $(71 \%)$ proved to have PCM Gomez I and II, while of the children with positive tuberculin but with negative röntgen photos only 14 children $(13 \%)$ had PCM Gomez I and II. From this it is clear that there exists a close relationship between nutritional status and demonstrable tuberculous lesions in the lungs.

Although we cannot prove which factor comes first, from the result it is evident that :

1. Poor nutritional condition seems to develop in the presence of tubercu-

\section{REFERENCES}

1. ABDUL RIVAI; M. TAHER DJALIL ANNA D. ALISJAHBANA and SUGIRI : BCG vaccination on newborn Infants with freeze dried $B C G$ vaccine made by $P N$ Biofarma. Paediatr. In dones. 11 : 219 (1971).

2. COMSTOCK, G.W.; LWISAY, V.T. and WOOLPERT, S.F.: The prognosis of a positive tuberculin reaction in childhood and adolescence. Am. J. Epidemiol. 99 : 131 (1974). lous infection among babies under 6 months old.

2. Specific treatment, without special attention to extra feeding, has resulted in a remarkable recovery of body weight after several months of therapy.

Thus, it appears that tuberculous infection in these children, though clinically silent, was a substantial cause of malnutrition. For the whole nation it means that primary tuberculosis in Indonesia is a major determinant factor of malnutrition and therefore diagnosis and aggresive therapy deserves far greater attention than presently available. Roughly 1 out of 150 Indonesian adults has positive TB sputum, but 1 out of 4 to 1 out of 2 children is affected by tuberculosis and its detrimental nutritional consequences even if secondary tuberculosis never arises. Manual for the standardization and evaluation of data for the assessment of the nutritional health of a community using field survey techniques in rural areas. Jakarta, 1971.

4. GOMEZ, F.; RAMOS-GALVON, H. FRENK, S.; MUNOS, J.C.; CHAVES, R. and VAZQUAS, J. : Mortality in second and third degree malnutrition. J. trop. Pediatr. 2 : 77 (1956). 
5. LIEM TJAY TIE : Tentang tuberculose anak-anak. Ber. Tuberk. Indones. 2 : 12 (1955).

6. SAMALLO, L.G.J.: Penilaian hasil vaksinas! BCG setjara besar-besaran di Indonesia. Ber. Tuberk. Indones. 5 : 1 (1958).

7. SHENAN, D.H. : Tuberculosis control in developing countries (Livingstone, Edinburg/London 1968).
8. SUTEDJO : Pediatri pencegahan. Proc. KPPIK-FKUI, p. 235, 1965.

9. SUTEDJO; MOH. SUGIONO; ROHTIATMO, $\mathrm{K}$. and SUDIJANTO : Morbidity in outpatients attending the Department of Child Health, Medical School, University of Indonesia/Dr. Tjipto Mangunkusumo General Hospital, Jakarta. Pediatr. Indones. 8 : 235 (1968). 